\title{
Factors Influencing Job Seeker's Intention to Use E-Recruitment: Evidence from a State University in Sri Lanka
}

\author{
E.M.M.S. Ekanayaka*, Prof. Prasadini Gamage \\ Department of Human Resource Management, Faculty of Commerce and Management Studies, University of \\ Kelaniya, Sri Lanka \\ *Corresponding Author: E.M.M.S. Ekanayaka, Department of Human Resource Management, Faculty \\ of Commerce and Management Studies, University of Kelaniya, Sri Lanka
}

\begin{abstract}
With the advent of Internet Technology, the way of executing Human Resource Management function has been dramatically changed over the past. Shifting from traditional way of (labour intensive) delivering human resource management function towards more efficient, cost effective means (technology intensive) has now become the key consideration of the human resource management literature. Many firms now use electronic recruitment (e-recruitment) rather than conventional method of employee recruitment. Moreover, potential job candidates are more interested in searching and applying for job openings through internet. For the purpose of generating appropriate applicant pool, firms tend to develop attractive, content rich, easy to use and user-friendly recruitment through their own website or via job portals. However, the effect of the e-recruitment on candidates' intention to apply for the job is under studied in the Sri Lankan context. Thus, the objective of this paper is to explore the impact of e-recruitment on candidates' intention to apply for the job openings. Since undergraduates are intensively used internet to search for job openings, 60 undergraduates those who study in final year are surveyed through self-administered questionnaire. Simple regression reveals that ease of use and perceived usefulness significantly influences on job seekers' intention to use e-recruitment. And also perceived trust has no impact on job seekers' intention to use erecruitment.The findings of the study would be important to the firms to effectively carry out e-recruitment to optimize the appropriate pool of applicants and to design an attractive job portal.
\end{abstract}

\section{INTRODUCTION}

Recruitment of employees is at the core of the Human Resource Management (HRM) process and it plays a very important role in an organizational scenario. In the human resource management field, recruitment is the process of finding and acquiring the most suitable candidates for the vacancies of the organization at the right time and in a cost-effective way. In order to achieve the recruitment goals, recruitment programs should arrange so that the qualified candidates attract to the job openings. The traditional recruitment methods should be replaced with most technologically advanced recruitment methods to achieve recruitment goals. To survive in this competitive market, companies should have to adopt to the internet technology, especially in finding the suitable candidates to fill crucial positions in a company. According to Busser and Davis (2001) as cited in Troshani, Jerram and Gerrard (2010), changing traditional recruitment methods into online recruitment methods now became the latest trend in the recruitment process. The presence of electronic human resource management (e- HR) has increased since the mid-1990 (Boudauouk\&Ruel, 2005). Hadlogten (2009) as cited in Alsultanny and Alotaibi (2015), the first introduction of the internet as a recruitment tool was in the mid-1990s.

In recent years, e-recruitment is becoming the most effective and efficient way of hiring potential employees. According to Ensher, Nielson, and Grant-Vallone (2002) as cited in Galhena and Liyanage (2014), transformation of conventional ways of (labor intensive) executing HRM function towards more efficient, cost-effective (technology intensive) ways has become the key consideration of HRM.

Online recruitment (OR) also called as e- recruiting, cyber recruiting or internet recruiting, which is a formal way of sourcing job information online (Galanaki, 2002). E-recruitment is a novel concept to some extent. When the extensive increase of the use of intent at universities and IT companies, the 
systematic reference to the e-recruitment in the HR journals begins in the mid-1990s (Monavarian, Kashi, \& Ramin-mehr, 2003). Since the newness of the e-recruitment concept, the consists of erecruitment differ according to the different authors; for example e-recruitment can be defined as online advertising of companies' job vacancies (Galanaki, 2002), as a way of identifying and attracting potential candidates by using the internet (Parry \& Wilson, 2009), or as a recruitment tool through the internet (Reddy, Mamatha, \& Balaram, 2018) However, those definitions narrowly explain the expanded use of the internet as a source of recruitment. Holm (2010) comprehensively defines e-recruitment as "organization of the recruitment process and activities, which, by means of technology and human agents, facilitate time- and space-independent collaboration and interaction in order to identify, attract, and influence competent candidates".

Since globalization is spreading all over the world Sri Lanka is being also affected by it and the challenges faced by organizations under the recruitment remain same as the global context, the use of efficient systems like e-recruitment is also an emerging need in Sri Lanka (Vivek, 2018). Furthermore, Vivek (2018) stated that Sri Lanka still has not a considerable movement towards online recruitment, even in the present situation, there are few large companies including multinational companies practicing posting job openings on corporate websites and the less number of sophisticated job board like Topjobs existing.

Changing the individual's mindset and behavior towards new initiatives is usually not an easy task, because of the novelty of e-recruitment concept in the HRM field, job seekers still rely on traditional recruitment methods (Galhena \& Liyanage, 2014).

The aim of this study is to examine the factors affecting to adaptation of the e-recruitment which could be useful for organizations and recruitment firms. Many empirical studies on online recruitment adaptation have tested the Technology Acceptance Model (TAM) developed by Devis (1989) and proved that this model is appropriate to study behavioral intention on e-recruitment of job seekers. TAM is the most used model in IT literature (Monavarin, Kashi, Ramir-mehr, 2010).

Alsultanny and Alotaibi (2015) stated that, in order to search a job via the internet, around 4 million people open their web browser every day. Many researchers recently highlighted that the importance of online recruitment to reduce time and cost while it supports to acquire a large pool of potential candidates as a recruitment method. However, Vivek (2018) stated that until recent years, it was hard to see any significant movement towards internet-based recruitment and selection system (erecruitment method) being widely used in Sri Lanka. Furthermore, the effect of the e-recruitment on candidate's intention to apply for the job is understudied in the Sri Lankan Context (Galhena\& Liyanage, 2014). Therefore the purpose of this study is to explore the factors affecting job seekers' intention to use e-recruitment.

\section{RESEARCH CONTEXT}

As Peter (2001) cited in Tong (2009), stated that generally, there are two categories of jobseekers: active and passive. Passive job seekers are those employed jobseekers that already have a good position but will apply if they see another job of interest, whereas active candidates may include the dissatisfied, less employable job seekers and passive candidates are of higher quality than active candidates. Furthermore, Tape (2011) as cited in Alsultanny and Alotaibi (2015) especially, job searching through the internet is a totally common phenomenon among the students.

Sarks and Ashforth in 1999 as cited in Liyanange and Galhena (2014) stated that active job searching behavior can be identified among the fresh graduates. Accordingly, this study was conduct based on the undergraduate of University of Kelaniya. Today, the University of Kelaniya is one of the major national universities in Sri Lanka which has a proud history of more than 125 years with a vision of to become a centre of excellence in creation and dissemination of knowledge for sustainable development. And mission of the university is to nurture intellectual citizens through creativity and innovation, who contribute to the national development.

Majority of final and third-year students of University of Kelaniyaare engaging with internship programs due to it is mandatory for them to participate for it. Even though their mandatory training period over, some students continue their training program for the purpose of gaining work experience. And also some university students engage in permanent jobs while they fulfill their 
academic requirements. Hence university students often use various recruitment methods for finding a job. Therefore it is important to examine the job searching behavior in university students.

According to the UGC annual report - 2016, total graduate output was 33,072 in 2015. Bellow table shows the graduate output for 2011 to 2015 .

Table1: Graduate Output by Faculty / Academic Stream 2011-2015

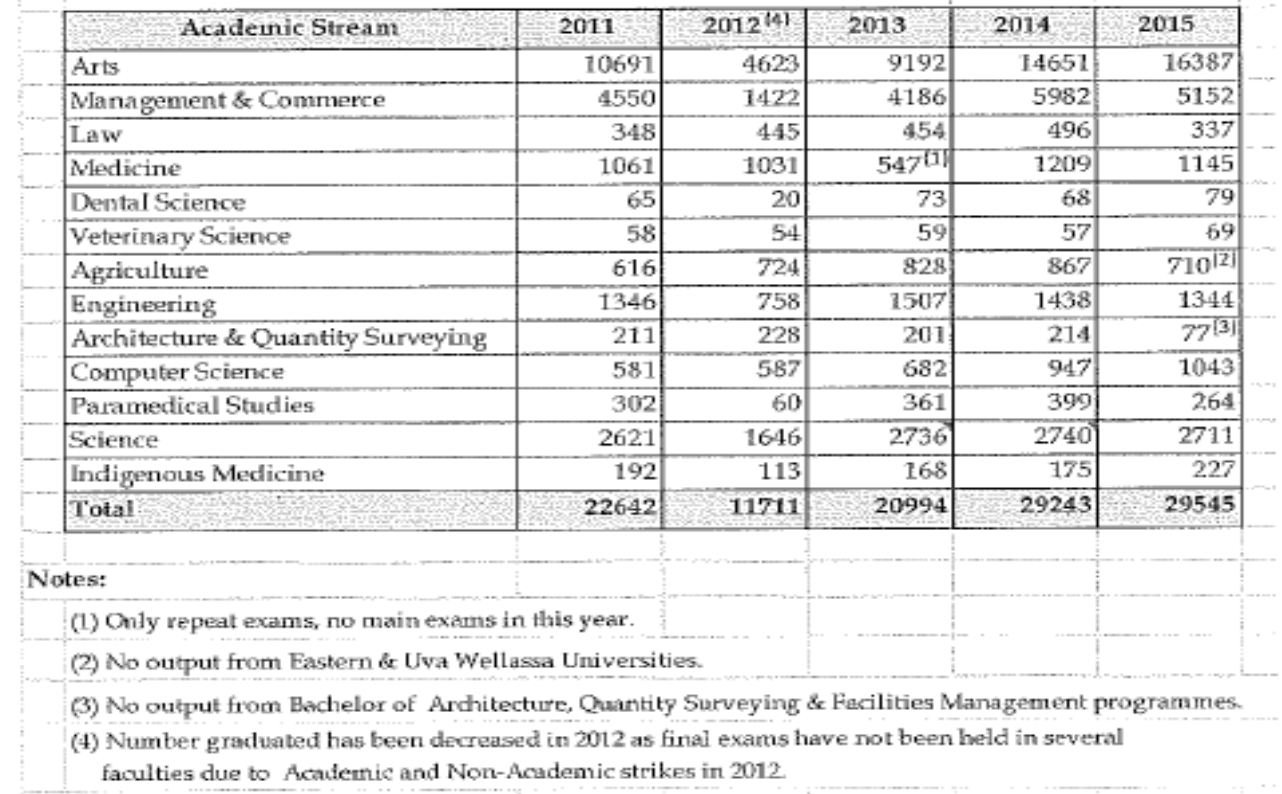

Source: UGC Annual Report-2016

Above table (Table 1) shows that majority of graduates represent the faculty of art and faculty of management-commerce. As well as most of the unemployed graduates belong to this faculties' degree holders. Therefore, their job searching intention is high.

\section{Problem Statement}

Many researchers recently highlighted that the importance of online recruitment to reduce time and cost for both job seekers and companies which use e-recruitment as recruitment method. However, Vivek (2018) stated that until recent years, it was hard to see any significant movement towards internet-based recruitment and selection system (e-recruitment method) being widely used in Sri Lanka. Furthermore, the effect of the e-recruitment on candidate's intention to apply for the job is understudied in the Sri Lankan Context.

As below figure shows the internet penetration rate in Sri Lanka from 2005 to 2016 has rapidly increased.

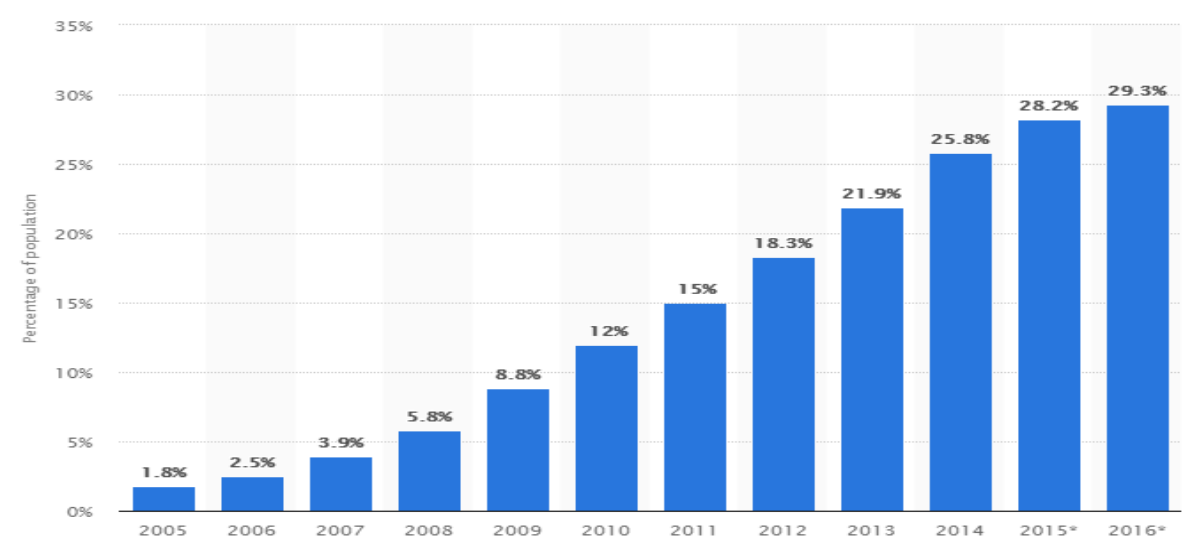

Figure1: Internet penetration rate in Sri Lanka From 2005 to 2016

Source: Internet Live Stats: www.InternetLiveStat.com 
According to the above figure, approximately $29.3 \%$ Sri Lankan population had access to the internet in 2016. Even though, it is difficult to find statistics results regarding increase of erecruitment usage in the Sri Lankan context, it can be seen that the job seekers tend to use erecruitment as a job searching tool. E-recruitment websites designers and organizations should have sound understanding about the factors drives job seekers intention to use erecruitment. Therefore, this study focus on finding out What factors affecting to job seekers intention to use e-recruitment in Sri Lankan context.

\section{OBJECTIVES OF THE STUDY}

\subsection{General Objective}

The purpose of this study is to examine the factors affect to job seekers' intention to use erecruitment.

\subsection{Specific Objectives}

- To identify the impact of Perceived Usefulness (PU) on job seekers' intention to use erecruitment.

- To identify the impact of Perceived Ease of Use (PEOU) on job seekers' intention to use erecruitment.

- To identify the impact of Perceived Trust (PT) on job seekers' intention to use e-recruitment.

\subsection{Research Questions}

- Does the Perceived Usefulness (PU) positively impact on job seeker's intention to use erecruitment?

- Does the Perceived Ease of Use (PEOU) positively impact on job seeker's intention to use erecruitment?

- Does the Perceived Trust (PT) significantly impact on job seeker's intention to use e-recruitment?

\section{LiTERATURE REVIEW}

\subsection{Literature on E-Recruitment}

Recruitment plays a key role to achieve strategic goals and develop human capital within the organization (Cober, Brown, Blumental, Doverspike, \& Levy, 2000). Recruitment can be defined as "practices and activities carried on by the organization with the primary purpose of identifying and attracting potential employees" (Baber, 1998, p. 5). E-recruitment is most open area to the internet technology in the field of HRM (Kashi \& Zheng, 2013).It can be seen drastic increases in erecruitment over the past decades . According to Galanaki (2002) as cited in Monavarian et al., (2010), stated that the term e-recruitment denote the formal way of obtaining job information online. E- recruitment is fairly a novel concept. Therefore, different authors have defined it as different ways. According to Borstorff, Marker and Bennett (2006) as cited in Monavarian et al.,(2010), "Online recruiting is the process of recruiting through company websites or commercial job sites that promotes employment opportunities and retrieves potential employee information".

Barber (2006), from Institute for Employment Studies (UK) as cited in Kumar and Priyanka (2014), studied the benefits and challenges of Internet recruiting. The article concludes that access to a wider pool of applicants and promotion of a company's reputation and brand are frequently mentioned by HR specialists who analyze the strengths of the e-recruiting.

Pin, Laorden and Saenz-Diez (2001) as cited in Kumar and Priyanka (2014), recorded that 167 firms in Europe in which $83 \%$ were showing higher performance and were using online HR practices. In those firms $44 \%$ were those who used e-recruitment to attract candidates for vacant positions.

Galanaki (2002) had conducted a descriptive study on the decision to recruit online, involving 99 UK IT companies whose shares were traded in London stock exchange. A survey was carried out, in the form of a postal questionnaire, followed by an interview in which 34 companies replied. The author found that internet agencies provide the company with fewer but substantially better applicants than traditional recruitment agencies. 
According to the finding of previous researches it is shown that in a global context using erecruitment as a recruitment tool has consistently increased. As well as most job seekers adopted to the e-recruitment methods rather relying on traditional recruitment methods.

When it comes to Sri Lankan context, several companies have been established e-recruitment especially for publishing companies' job openings. Job seekers are keen to such websites since it provides collection of job openings (Liyanage \& Galhena, 2014)

However, Weerakoon \& Gamage (2012), stated that e-recruitment is understudied in Sri Lanka context. And also the effect of the e-recruitment on candidates' intention to apply for the job is understudied in the Sri Lankan context (Liyanage \& Galhena, 2014).

This paper develops a research model based on the technology acceptance model (TAM) to study the factors affecting to job seeker's intention to use e-recruitment.

\subsection{Technology Acceptance Model}

The technology acceptance model (TAM) is widely applied in studies of Internet-related behavior (Cho, Lee, \& Liu, 2011) and it is one of the most influential approaches to explain and predict user acceptance of information systems (Davis, 1989). TAM has become one of the most widely used and empirically validated models within information systems research (King \& He, 2006).

According to Davis (1989), the goal of TAM is to provide an explanation of the determinants of computer acceptance that is generally capable of explaining user behaviour across a broad range of end-user computing technologies and user populations.

TAM has been extensively tested and validated by previous studies. Therefore, it is commonly accepted for the study of Internet-related behavior (Cho, Lee, \& Liu, 2011).

\subsection{Job Seeker's Behavioral Intention}

According to TAM, behavioural intention defines the actual use of a given IS system and therefore determines technology acceptance (Davis, 1989). In the e-recruitment context, this study hypothesize that job seeker intention is determined by how users come to accept and use a technology in the perspective of behavior.

Usually, it is hard to adjust the individuals' attitudes and behaviors to familiarize into new initiatives. As e-recruitment is fairly new phenomenon in the HRM field some of job seekers are still highly relying on traditional recruitment methods. Hence, from the company standpoint, it is important to adjust the attitudes and behaviors of the potential job seekers and encourage them to use more on erecruitment method (Liyanage \& Galhena, 2014).

$\mathrm{Ng}$ and Burke (2006) in their study on the next generation at work explored the views, career expectations, and job search behaviors among a sample of business students. The authors conducted a field survey involving 20,771 students across Canada to understand the views of university students on jobs, organizations, careers and perception of their organizations. The study using multiple regression analysis found that cooperative students appear to have more realistic expectation, have better insights into their own abilities and desires, and report higher self-confidence. It also reported that the respondents had low expectations that their campus career offices would get them a job, and expected to use the internet more frequently in their job searches. This suggested a shift away from traditional recruitment mediums to more contemporary approaches such as internet.

\subsubsection{Perceived Usefulness (PU)}

The first construct is perceived usefulness. Usefulness is considered to be the most important determinant of attitude towards usage of new technology and was defined by Davis as "the degree to which a person believes that using a particular system would enhance his or her job performance". In a job-seeking circumstance, perceived usefulness of a Web site is the extent to which a job seeker believes that using the Web site will enhance his or her ability to acquire job information (Cho, Lee, \& Liu, 2011).

\subsubsection{Perceived Ease of Use (PEOU)}

The second construct is perceived ease of use. Davis defined this as "the degree to which a person believes that using a particular system would be free from effort" (Davis, 1989). Perceived ease of use 
is the degree to which a Web site is perceived by a job seeker to be easy to use in finding job information and thereby submitting his or her job application through the Web site.

\subsubsection{Perceived Trust (PT)}

Other than the perceived usefulness and perceived ease of use, the current study examines the influence of perceived trust on behavioral intention to use e-recruitment. Mayer et al. (1995) defined trust as behavioral, based on one person's beliefs about the characteristics of another person. Since, in a virtual environment, the degree of uncertainty of a transaction is higher than in a traditional setting, trust becomes an important factor. Therefore, Roca, Garcia, and Vega (2008) stated that the user's feelings of trust toward an e-service are an important determinant in considering his/her intentions to use, and usage behaviors related to any e-service. Furthermore, due to the increasing importance of data privacy and online security risk measures, it is deemed necessary to include the trust as a factor influencing job-seekers' intention to use online recruitment websites.

\subsection{Literature on TAM Model}

Cheng, Cheung and Change (2002) conducted a research to examine how customers perceive and adopt internet banking (IB) in Hong Kong. They developed a theoretical model based on the Technology Acceptance Model (TAM) with an added construct Perceived Web Security, and empirically tested its ability in predicting customers' behavioral intention of adopting IB. The results provide support of the extended TAM model and confirm its suitability in forecasting customers' intention of adoption of IB.

Gefen, Karahanna and Struab (2003) developed a model to understand online shopping acceptance among shoppers. According to the findings the consumer's intention to buy online depends on trust and the two believes identified by TAM which are perceived usefulness and perceived ease of use.

The study conducted in Malaysia by Tong in 2009, and modified Technology Acceptance Model (TAM) excluding the attitude construct as the core research framework while identifying Perceived Privacy Risk (PPR), Performance Expectancy (PE), Application-Specific Self-Efficacy (ASSE), and Perceived Stress (PS) as key external variables that form the research model for the study of erecruitment technology adoption. The results identified few key determinants to this technology adoption some of which include PS, PPR and PE.

Kashi and Zheng. (2013) used to extend TAM model to understand E-Recruitment acceptance in Iran. It was found that perceived usefulness played a more vital in determining the user behavioral intentions. It was also found that impression of the organizational website appeared to create interests in organization as a potential employer; hence, prompt applicants to apply for jobs.

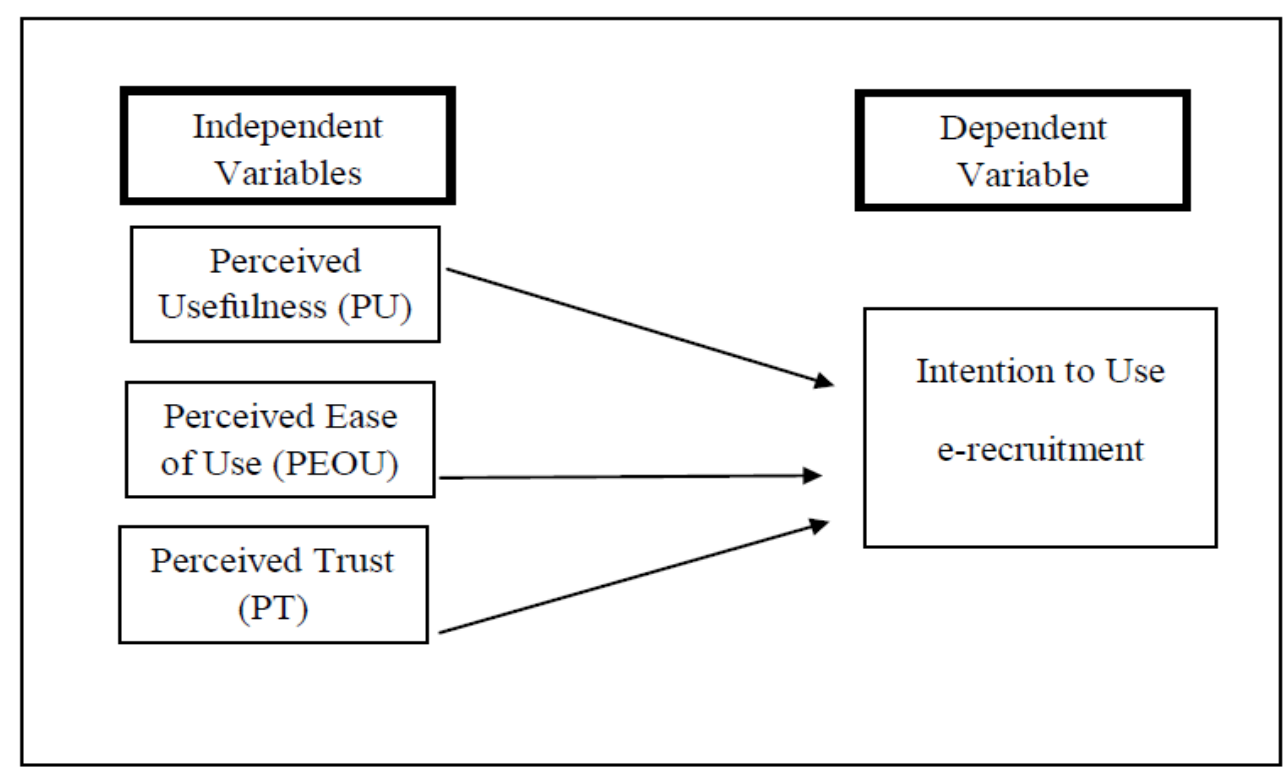

Figure2: Conceptual Framework

Source: Developed by researcher based on TAM model of Davis, 1989 


\section{AdVANCING OF HYPOTHESES}

Having considered to the evidences in literature recorded in this research, Perceived Usefulness, Perceived Ease of Use and Perceived Trust are recognized as the independent variables and the Job Seeker's Intention towards using e-recruitment is identified as the dependent variable.

To find out whether the relationships theorized in the conceptual research framework hold true, following hypotheses are drawn:

Let; $\mathbf{H}_{\mathrm{A}}$ : Alternate Hypothesis

$$
\mathbf{H}_{0} \text { : Null Hypothesis }
$$

\section{Hypothesis 1}

$\mathrm{H1}_{\mathrm{A}}$ : There is a positive relationship between Perceived Usefulness and Job seeker's intention to use e-recruitment.

H1 $1_{0}$ : There is a negative relationship between perceived usefulness and Job seeker's intention to use e-recruitment.

\section{Hypothesis 2}

$\mathbf{H 2} \mathbf{2}_{\mathrm{A}}$ : There is a positive relationship between perceived ease of use and job seeker's intention to use to e-recruitment.

$\mathbf{H} \mathbf{2}_{0}$ : There is a negative relationship between perceived ease of use and job seeker's intention to use e-recruitment.

\section{Hypothesis 3}

$\mathbf{H 3}_{\mathrm{A}}$. There is a significant relationship between perceived trust and job seekers' intention to use erecruitment.

$\mathbf{H 3}_{\mathbf{0}}$ There is no significant relationship between perceived trust and job seekers' intention to use erecruitment.

\section{Overall ReSEarch Design}

This study is named as "A study on factors affecting to job seeker's intention to use e-recruitment with special reference to final year undergraduates of University of Kelaniya in Sri Lanka'. This is a quantitative type study which tries to find out the solution for the research problem of "What factors affecting to job seekers intention to use e-recruitment in Sri Lankan context ?" As the current study tries to test the formulated hypothesis and established relationships in the model, this work would be considered as an explanatory research. Further, this is a cross sectional examination as information will be gathered just in a specific purpose of time and it won't repeat. Additionally, researcher's obstruction will be least in the present investigation and in the meantime this will be a field think about. Unit of examination will be at the individual level; final year undergraduate of university of Kelaniya.

The study will be conducted among 60 final year undergraduates at university of Kelaniya in Sri Lanka and the sample will be drawn through simple random sampling. Data will be collected pretested, standard questionnaire which has met the accepted standards of validity and reliability. Collected data will be analyzed Satirical Package for Social Science 23.0 (SPSS). Further, frequency analysis, correlation test and regression analysis will be used to analyze data in order to test the advanced hypotheses.

\subsection{Population}

The population concerned for the study includes all the final year undergraduates at university of Kelaniya in Sri Lanka, out of which a representative sample will be taken.

\subsection{Sample and the Sampling Techniques}

Simple Random sampling would be used to select a representative sample. A total of 60 final year undergraduates from university of Kelaniya have been selected. 


\subsection{Testing of Hypotheses}

\subsubsection{Sample Composition}

The questionnaire was distributed among 60 final year undergraduate of University of Kelaniya. Fifty Seven (57) out of the sixty has responded to the questionnaire and all the responses were eligible for the purpose of analysis though SPSS, it resulted a 95\% response rate out of the total sample.

Gender is the main distinguish between male and female. The survey responses have been divided between two genders as males and females. According to the data collected, majority of respondents are females $(57.9 \%)$ while $42.1 \%$ males.

According to the Faculty of Studying Composition of the Sample majority of the respondents belongs to the Commerce \& Management Faculty. It is $47.4 \%$ and nearly a half of the entire respondents. The $23.8 \%$ respondents belongs to the Science Faculty and it is similar to the Faculty of Social Science representation. In addition to that, Faculty of Humanities represent $7 \%$.

And also (32\%) respondents of the study sample were employed undergraduates and $39(68 \%)$ of the study sample were unemployed undergraduates.

When consider about the Internet Experience Composition of the Sample, 5 (8.8\%) respondents of the study sample have less than 2 years of internet experience; 7 (12.3\%) respondents have a 2-3 years of internet experience; 18 (31.6\%) respondents have a 4-5 internet experience; $15(26.3 \%)$ respondents of the study sample have a 5-6 years of internet experience and $12(21.1 \%)$ respondents of the sample have more than 7 years internet experience. Therefore, it indicated that most of the job seekers have experience in using Internet, which makes it easier for themuse e-recruitment.

According to the Average time of searching jobs through E-recruitment composition of the sample, majority of the respondents are spending average time of searching jobs though E- recruitment for less than 30 minutes per day. It is $59.6 \%$ and more than half of the entire respondents. The second major category of average time of searching jobs though E-recruitment is, 30 minutes up to 1 hour. It is $26.3 \%$ of the entire sample. $3(5.3 \%)$ of the respondents of the study sample almost none spending average time of searching jobs though E-recruitment. Other respondents are spending average time of searching jobs through E- recruitment for 1-2 hours and more than two hours which represent a proportion of $5.3 \%$ and $3.5 \%$ respectively.

$\mathbf{H 1}_{\mathrm{A}}$ : There is a positive relationship between Perceived Usefulness and Job seeker's intention to use e-recruitment.

Table2: Correlation Statistics of Perceived Usefulness

\begin{tabular}{|l|l|l|l|}
\hline \multicolumn{2}{|c|}{ Intention to Use } & Intention to Use & Perceived Usefulness \\
\cline { 2 - 4 } & Sig. (1-tailed) & 1 & $.566^{* *}$ \\
\cline { 2 - 4 } & $\mathrm{N}$ & & .000 \\
\hline \multirow{3}{*}{ Perceived Usefulness } & Pearson Correlation & $.566^{* * *}$ & 57 \\
\cline { 2 - 4 } & Sig. (1-tailed) & .000 & 1 \\
\cline { 2 - 4 } & $\mathrm{N}$ & 57 & 57 \\
\hline
\end{tabular}

**. Correlation is significant at the 0.01 level (1-tailed).

As shown in the table 2 Pearson Correlation coefficient between Perceived Usefulness and Intention to Use is .566. It suggests that there is a significant moderate positive relationship exists between Perceived Usefulness and Intention to Use. As the above table shows, the significant value (.000) is smaller than the desired level of significance. 0.01) at $99 \%$ confidence level, the resulted correlation coefficients, .566 is statistically significant. Therefore, alternative hypothesis $\left(\mathrm{H}_{\mathrm{A}}\right)$ is accepted and rejecting the null hypothesis.

Table3: Regression Model Summary-Perceived Usefulness

\begin{tabular}{|l|l|l|l|l|l|}
\hline Model & R & R Square & Adjusted R Square & Std. Error of the Estimate & Durbin-Watson \\
\hline 1 & $.566^{\mathrm{a}}$ & .320 & .308 & .60834 & 2.237 \\
\hline
\end{tabular}

According to table $3 \mathrm{R}$ Square stands for 0.320 which state that there is $32 \%$ of positive impact of perceived usefulness on job seekers' intention to use e-recruitment. 
Table4: Perceived Usefulness - ANOVA ${ }^{a}$

\begin{tabular}{|c|c|c|c|c|c|c|}
\hline \multicolumn{7}{|c|}{ Table 4Perceived Usefulness - ANOVA ${ }^{\mathrm{a}}$} \\
\hline \multicolumn{2}{|c|}{ Model } & Sum of Squares & $\mathrm{df}$ & Mean Square & $\mathrm{F}$ & Sig. \\
\hline \multirow[t]{3}{*}{1} & Regression & 9.591 & 1 & 9.591 & 25.918 & $.000^{\mathrm{b}}$ \\
\hline & Residual & 20.354 & 55 & .370 & & \\
\hline & Total & 29.945 & 56 & & & \\
\hline
\end{tabular}

$\mathbf{H} \mathbf{2}_{\mathrm{A}}$ : There is a positive relationship between perceived ease of use and job seeker's intention to use to e-recruitment.

Table5: Correlations Statistics of Perceived Ease of Use

\begin{tabular}{|l|l|l|l|}
\hline \multicolumn{2}{|c|}{ Intention to Use } & Intention to Use & Perceived Ease of Use \\
\cline { 2 - 4 } & Pearson Correlation & 1 & $.707^{* *}$ \\
\cline { 2 - 4 } & Sig. (1-tailed) & & .000 \\
\cline { 2 - 4 } & $\mathrm{N}$ & 57 & 57 \\
\hline \multirow{3}{*}{ Perceived Ease of Use } & Pearson Correlation & $.707^{* *}$ & 1 \\
\cline { 2 - 4 } & Sig. (1-tailed) & .000 & 57 \\
\cline { 2 - 4 } & $\mathrm{N}$ & 57 & 57 \\
\hline
\end{tabular}

**. Correlation is significant at the 0.01 level (1-tailed).

Table 5indicates that the correlation coefficient between perceived ease of use and intention to use is .707. It suggests that there is a significant strong positive relationship exists between perceived ease of use and intention to use. As the table 4 shows, the significant value (.000) is lower than the desired level of significance. 0.01) at $99 \%$ confidence level, the resulted correlation coefficients, .707 is statistically significant. Therefore, alternative hypothesis $\left(\mathrm{H} 2_{\mathrm{A}}\right)$ is accepted and rejecting the null hypothesis.

Table6: Regression Model Summary Perceived Ease of Use

\begin{tabular}{|l|l|l|l|l|}
\hline Model & R & R Square & Adjusted R Square & Std. Error of the Estimate \\
\hline 1 & $.707^{\mathrm{a}}$ & .500 & .490 & .52199 \\
\hline
\end{tabular}

According to table $6 \mathrm{R}$ Square stands for 0.500 which state that there is $50 \%$ of positive impact of perceived ease of use on job seekers' intention to use e-recruitment.

Table7: Perceived Ease of Use - ANOVA ${ }^{a}$

\begin{tabular}{|l|l|l|l|l|l|l|}
\hline \multicolumn{2}{|l|}{ Model } & Sum of Squares & df & Mean Square & F & Sig. \\
\hline \multirow{3}{*}{1} & Regression & 14.959 & 1 & 14.959 & 54.900 & $.000^{\mathrm{b}}$ \\
\cline { 2 - 7 } & Residual & 14.986 & 55 & .272 & & \\
\cline { 2 - 7 } & Total & 29.945 & 56 & & & \\
\hline
\end{tabular}

$\mathbf{H} 3_{\mathbf{A}}$. There is a significant relationship between perceived trust and job seekers' intention to use erecruitment.

Table8: Correlations Statistics of Perceived Trust

\begin{tabular}{|l|l|l|l|}
\hline \multicolumn{2}{|c|}{ Intention to Use } & Intention to Use & Perceived Trust \\
\cline { 2 - 4 } & Pearson Correlation & 1 & .185 \\
\cline { 2 - 4 } & Sig. (2-tailed) & & .168 \\
\cline { 2 - 4 } & $\mathrm{N}$ & 57 & 57 \\
\hline \multirow{3}{*}{ Perceived Trust } & Pearson Correlation & .185 & 1 \\
\cline { 2 - 4 } & Sig. (2-tailed) & .168 & 57 \\
\cline { 2 - 4 } & $\mathrm{N}$ & 57 & 57 \\
\hline
\end{tabular}

Table 8 indicates that the correlation coefficient between Perceived Trust and Intention to Use is .185. The significant value (.168) is greater than the desired level of significance 0.05 at $95 \%$ confidence level, the resulted correlation coefficients, .185 is statistically insignificant.

Accordingly, there is no statistically significant relationship between perceived trust and intention to use e-recruitment. Therefore, null hypothesis $\left(\mathrm{H}_{3}\right)$ is accepted and rejecting the alternative hypothesis.

\section{FINDINGS}

Similar to previous studies (Alsultanny \& Alotaibi, 2015), this study confirmed that the Technology Acceptance Model (TAM) is a useful theoretical model for understanding and explaining users' behavioral intention to accepting new technologies (Weerasinghe, 2016). 
This study aims to assess factors that affect to the job seekers' intention to use e-recruitment. Based on the TAM model and existing literature, the conceptual framework was developed with the independent variables of perceived usefulness, perceived ease of use, perceived trust. The results were intended to be used to acquire a better understanding of what factors affecting to job seeker's intention to use e-recruitment.

According to the study conducted by Galhena and Liyanage (2014), it was revealed that the Perceived ease of use and perceived usefulness significantly influences on candidates' behavioural intention to use e-recruitment in the Sri Lankan context. Alsultanny and Alotaibi (2015) revealed that, usefulness and ease of use significantly correlate with the attitude towards using e-recruitment while attitude strongly correlate with their intention to use e- recruitment. Having considered that, it seems that the results of the current study agree with the results of previous studies, as the current study results that, positive relationships between perceived usefulness and intention to use e-recruitment and positive relationship between perceived ease of use and intention to use e-recruitment. The simple regression analysis proves that the perceived usefulness and perceived ease of use have positive relationships with intention to use e- recruitment, which have been established with the strength of beta values of 0.566 and 0.707 respectively.

Trust has been recognized as a critical factor in the online environment(Gefen, Karahanna, \& Straub, 2003). However, Pavon and Brown (2010) found that trust has no significant influence on usage intention by job-seekers in South Africa, as trust is normally more associated with financial transactions rather than job-seeking. Accordingly, the result of this study also agree with the previous research findings, because the findings of the current study also indicate that the trust has no significance influence on job seekers' intention to use e-recruitment.

\subsection{Implications of the Study}

Because of recruitment is a key for organizations to maintain competitiveness and high productivity, it is important to use cost effective and efficient recruitment methods like e-recruitment. Furthermore, having sound understanding about job seekers' perception and the factors drive their intention to use online recruitment, leads to obtain more benefits for organizations.

As well as the number of internet users are increasing day by day. People can gain numerous benefits by using internet such as reduce time, effortlessness, reduce cost, access to the wide range of information. Since the use of internet has become more impacted things in human activities, the use of internet as a job searching tool has also increased.

Accordingly, it is important to understand the factors drives job seekers intention to use e-recruitment. Several previous studies revealed some important factors which should be considered when carrying out online recruitment.

According to the findings of current study, perceived usefulness and perceived ease of use influence to the job seekers' intention to use e-recruitment. Therefore, the career section of organizations' website and job portals should be designed so that it is easy to use for jobseekers and it is useful to job seekers.

Moreover, online job providers need to provide useful, easy web-based recruitment to job seekers and through the use of it, can encourage job seekers to apply for jobs via e-recruitment services.

Furthermore, this study provide insight for e-recruitment service providers to rethink about their current practices and revise their practices so that it will be more productive.

And also this provides variety of information related to this context for who are interested. Furthermore, this study provides theoretical and practical knowledge with the research guide for the university students and other persons who are interested to learn.

\section{CONCLUSION}

Having considered all the factors enumerated in this study, it can be concluded that there is a significant positive moderate relationship between perceived usefulness and job seekers' intention to use e-recruitment. And further, it was found that strong positive relationship between perceived ease of use and job seeker's intention to use e-recruitment. In addition to that it was found that, there is no significant relationship between perceived trust and job seekers' intention to use e-recruitment.

The main objective of this study was to examine the factors affect to job seekers' intention to use erecruitment. The result found that there are two factors namely job seeker's perceived usefulness and perceived ease of use impacted to job seekers' intention to use e-recruitment. 
In addition to that, the study endeavored to check the impact of perceived usefulness on job seekers' intention towards using e-recruitment. The result revealed that there is a moderate positive impact of perceived usefulness on job seeker's intention to use e-recruitment.

Further, the second specific objective, which was to check the impact of perceived ease of use on job seekers' intention to use e-recruitment. It also revealed that there is a strong positive impact of perceived ease of use and job seekers' intention to use e-recruitment.

And the third specific objective was to identify the impact of perceived trust on job seekers' intention to use e-recruitment. The result of this study revealed that there is no significant impact of perceived trust on job seekers' intention to use e-recruitment in Sri Lankan context. As such, all the objectives (i.e. the main objective and the three specific objectives) are achieved. Furthermore, it is suggested to future researchers to increase the sample size and to add more factors relating to e-recruitment intention in order to obtain a clear and most accurate results.

\section{RECOMMENDATIONS}

According to the findings of this study, it was revealed that there is a moderate positive significant relationship between perceived usefulness and job seekers intention to use e-recruitment. As such, it is recommended the e-recruitment service providers to consider this factor when they designing erecruitment web sites. In order to increase usefulness they can include information regarding salary, benefits, and rewards and other organizational policies and practices so that the job seekers' can make the decision on their future employer. Through the useful e-recruitment sites job seekers can gather information like effective resume writing, interviewing information, continuous education through the e-recruitment. These information leads to increase job seekers' intention to use e-recruitment. It indicate that, job seekers prefer to adopt the e-recruitment, if it is easy for them to use comparing other recruitment methods (Tong, 2008).

Furthermore, this study revealed that perceived ease of use and job seekers' intention to use erecruitment has strong positive relationship. Therefore it is recommend to design easy e-recruitment systems so that job seekers can easily adopt and can be use with less effort.

\section{LIMITATIONS OF THE STUDY}

The study involves only final year undergraduate of university of Kealaniya, and the sample was limited to 60 participants. If the scope the review spread to the other universities with more sample size, the result of the current study can be differ.

Current research was limited to three factors which affect to intention to use e-recruitment. There are some other factors such as perceived enjoyment, perceived stress etc. Therefore, the research can be further developed by adding new variables.

And also the results of the study may not be accurate as the entire study depends on the personal views of respondents through the questionnaire.

\section{REFERENCES}

[1] Alsultanny, Y. A., \& Alotaibi, M. F. (2015). Evaluating the Factors Affecting on Intension to Use of ERecruitment. American Journal of Information Science and Computer Engineering, 1(5), 324-331.

[2] Baber, A. (1998). Recruiting employees: Individual and organizational perspective. Thousand Oaks,CA: Sage Publications.

[3] Cho, S., Lee, W., \& Liu, J. (2011). E-Recruitment: Effects of Enjoyment and Attitudes toward Web Sites on Corporate Image and intention to apply. International CHRIE Conference-Refereed Track.

[4] Cober, R. T., Brown, D. J., Blumental, A. J., Doverspike, D., \& Levy, P. (2000). The quest for the qualified job surfer: It's time the public sector catches the wave. Public Personnel Management, 29(4), 479 -494. https://doi.org/10.1177/009102600002900406

[5] Davis, F. D. (1989). Perceived Usefulness, Perceived Ease of Use, and User Acceptance of Information Technology. MIS Quarterly, 13(3), 319-340. https://doi.org/10.2307/249008

[6] Eddy S.W. Ng, Ronald J. Burke, (2006) the next generation at work-business students' views, values and job search strategy: Implication for universities and employers, Education + Training, 48 (7),478-492, https://doi.org/10.1108/00400910610705872

[7] Galanaki, E. (2002). The decision to recruit online: A descriptive study. Career Development International, 7(4), 243-251. https://doi.org/10.1108/13620430210431325 
[8] Gefen, D., Karahanna, E., \& Straub, D. W. (2003). Inexperience and Experience With Online Stores : The Importance of TAM and Trust, 50(3), 307-321.

[9] Holm, A. B. (2010). The Effect of E-recruitment On the Recruitment Process : Evidence from Case Studies of Three Danish MNCs Research Background, 570, 91-111.

[10] Kashi, K., \& Zheng, C. (2013). Extending Technology Acceptance Model to the E-recruitment Context in Iran. International Journal of Selection and Assessment, 21(1), 121-129. https://doi.org/10.1111/ijsa.12022

[11] King, R. W., \& He, J. (2006). A meta-analysis of the technology acceptance model. Information and Management, 43(6), 740-755.

[12] Kumar, A., \& Priyanka, S. (2014). A study on adoption of E-recruitment using Technology Acceptance Model (TAM) with reference to graduating students in universities in Bahrain. International Journal of Advance Research in Computer Science and Management Studies, 2(9), 377-383.

[13] Galhena, B., \& Liyanage, D.(2014). Effect of E-Recruitment on Behavioural Intention of Candidates: Empirical Evidence From Management Undergraduates in Sri Lanka. International Journal of Human Resource Management and Research (IJHRMR), 4(5),25-32. Retrieved from http://www.mgt.ruh.ac.lk/ pubs/pdf/ICME2014_OP_p277.pdf

[14] Gefen, D.,Karahanna,E., \& Staub D.W.(2003)Trust and TAM in Online Shopping: An Intergrated Model. MIS Quarlerly, 27(1), 51-90.

[15] Monavarian, A., Kashi, K., \& Ramin-mehr, H. (2010). Applying Technology Acceptance Model to Erecruitment Context. Researchgate.Net, (May). Retrieved from http://www.researchgate.net/publication/ 216524757_Applying_Technology_Acceptance_Model_to_E-recruitment_Context/file/cf63b1f2eedd704 eacd 5c9074e12d435.pdf

[16] Parry, E., \& Wilson, H. (2009). Factors influencing the adoption of online recruitment. Personnel Review, 38(6), 655-673. https://doi.org/10.1108/00483480910992265

[17] Reddy, M. N., Mamatha, T., \& Balaram, A. (2019). Iccce 2018 (Vol. 500). Springer Singapore. https://doi.org/10.1007/978-981-13-0212-1

[18] Vivek, R. (2018). E-Recruitment awareness and E-recruitment users in Srilanka, (05), 14-18.

[19] Weerakoon, K. G., \& Gamage, P. N. (2012). Impact of Ownership Structure on E-recruitment Practices in Banks in Sri Lanka. Global Journal of Enterprise ..., 4(Ii), 12-23. Retrieved from http://www.informatics journals.com/index.php/gjeis/article/view/3152

[20] Weerasinghe, W. G. C. (2016). Factors Affecting Online Printing Adoption by the Sri Lankan Printing Industry, 1-110.

[21] Tong, D. Y. K. (2009). A study of e-recruitment technology adoption in Malaysia. Industrial Management and Data Systems, 109(2), 281-300. https://doi.org/10.1108/02635570910930145

[22] Troshani, I., Jerram, C., \& Gerrard, M. (2010). Exploring the organizational adoption of Human Resources Information Systems ( HRIS ) in the Australian public sector. Association for Information Systems AIS Electronic Library (AISeL).

[23] Galanaki, E. (2002). The decision to recruit online: A descriptive study. Career Development International, 7(4), 243-251.

[24] Pavon, F. \& Brown, I., 2010, ' Factors influencing the adoption of the World Wide Web for job- seeking for South Africa', SA Journal of Information Management 12(1), Art. \#443, 9 pages. DOI:, 10.4102/sajim. v12i1.443

Citation: E.M.M.S. Ekanayaka, et.al. “ Factors Influencing Job Seeker's Intention to Use E-Recruitment: Evidence from a State University in Sri Lanka" International Journal of Managerial Studies and Research (IJMSR), vol 7, no. 8, 2019, pp. 1-12. doi: http://dx.doi.org/10.20431/2349-0349.0708001.

Copyright: (C) 2019 Authors. This is an open-access article distributed under the terms of the Creative Commons Attribution License, which permits unrestricted use, distribution, and reproduction in any medium, provided the original author and source are credited. 